\title{
DAMPAK INTELLECTUAL INTELLIGENCE (IQ) DENGAN KEBIASAAN PADA PRESTASI BELAJAR SISWA
}

\author{
Shendy Andrie Wijaya ${ }^{1)}$, Yusita Titi Hapsari' ${ }^{2)}$ \\ IKIP PGRI JEMBER \\ shendyandriewijaya@gmail.com
}

\begin{abstract}
The study was conducted aimed at obtaining the results of the impact of Intellectual Intelligence (IQ) with habits on learning achievement, students of Class XI Marketing 1 SMK Kartini Jember. In taking a sample of 35 students, through purposive sampling. Data collection methods are assisted by distributing questionnaires given to respondents. Whereas to prove the research hypothesis, the t test and F test were used. The results of the multiple linear regression analysis, there was a partially significant impact between Intellectual Intelligence (IQ) and habits on learning achievement, students of Class XI Marketing 1 at SMK Kartini Jember, this was proven from the results of t-test analysis, the value of t count $(2,373)>$ t table $(1,684)$ for the variable of intellectual intelligence (IQ) and t count $(2,130)>$ t table $(1,684)$ in the study habits variable. In the simultaneous test results obtained F count (10.498)> F table (3.30) with the level of sig. 0,000, so that the conclusion of the results of the study there is an impact between Intellectual Intelligence (IQ) with habits on student achievement.
\end{abstract}

Keywords: Intellectual Intelligence (IQ), Habits, Learning Achievements

Abstrak
Penelitian dilakukan bertujuan mendapatkan hasil dari dampak Intellectual Intelligence (IQ) dengan kebiasaan pada prestasi belajar, siswa kelas XI Pemasaran 1 SMK Kartini Jember. Dalam pengambilan sampel sebanyak 35 siswa, melalui purposive sampling. Metode pengumpulan data dibantu dengan penyebaran kuesioner yang diberikan pada responden. Sedangkan untuk membuktikan hipotesa penelitian, digunakan uji t dan uji F. Hasil analisis regresi linear berganda, terdapat dampak yang signifikan secara parsial antara Intellectual Intelligence (IQ) dengan kebiasaan pada prestasi belajar, siswa kelas XI Pemasaran 1 di SMK Kartini Jember, hal ini dibuktikan dari hasil analisis uji t diperoleh nilai $t_{\text {hitung }}(2,373)>t_{\text {tabel }}(1,684)$ untuk variabel kecerdasan intelektual (IQ) dan $t_{\text {hitung }}(2,130)>t_{\text {tabel }}$ $(1,684)$ pada variabel kebiasaan belajar. Pada pengujian secara simultan diperoleh hasil $\mathrm{F}_{\text {hitung }}$ $(10,498)>F_{\text {tabel }}(3,30)$ dengan taraf sig. 0,000 , sehingga kesimpulan hasil penelitian terdapat dampak antara Intellectual Intelligence (IQ) dengan kebiasaan pada prestasi belajar siswa.

Kata Kunci: Intellectual Intelligence(IQ), Kebiasaan, Prestasi Belajar 


\section{PENDAHULUAN}

Dalam menciptakan kondisi proses belajar agar siswa secara aktif serta efektif dengan mengembangkan potensi dirinya untuk memiliki kepribadian, kecerdasan, karakter, serta keterampilan yang diperlukan diri sendiri dan masyarakat luas merupakan pengertian dari pendidikan. Dalam tujuan pendidikan melahirkan generasi emas pada tahun 2045 perlu menghasilkan SDM yang berkarakter dan berkualitas untuk mengimbangi kemajuan IPTEK di era industri 4.0 agar menjadi lebih kompeten dalam segala aspek. Pendidikan dapat dilakukan melalui berbagai kegiatan, salah satunya melalui pendidikan formal dengan proses belajar di sekolah mulai tingkat sekolah PAUD sampai Perguruan Tinggi sesuai dengan tuntutan wajib belajar 12 tahun. Agar memperoleh proses pendidikan yang baik, maka perlu memperhatikan tingkat prestasi siswa dalam belajar. Ada beberapa unsur yang melatarbelakangi prestasi seorang siswa baik dari dalam diri siswa maupun luar siswa itu sendiri. Unsur internal salah satu indikatornya terdiri dari, motivasi belajar, intelegensi dan keberhasilan, sikap terhadap belajar, kebiasaan belajar, rasa percaya diri dan citacita siswa. (Dimyati dan Mudjiono: 2009). Namun yang paling terlihat faktor yang mempengaruhi keberhasilan siswa atau prestasi siswa itu sendiri yaitu faktor intelegensi atau kecerdasan, karena pada dasarnya setiap individu memiliki kemampuan yang berbeda yang mencakup tingkat kecerdasan (Inteligensi). Sejak baru lahir, kemampuan inteligensi yang memungkinkan seseorang berbuat sesuatu dengan strategi tertentu. Pengertian lain dari Inteligensi yaitu soal kesanggupan untuk menyesuaikan diri terhadap kebutuhan baru, melalui penggunaan alat-alat berpikir yang sesuai dengan tujuannya (Cholil dan Sugeng: 2011). Berdasarkan dari temuan penelitian bahwa siswa yang memiliki tingkat kecerdasan (IQ) yang tinggi maka dengan mudah mendapatkan nilai prestasi yang lebih baik, sedangkan apabila ada siswa yang memiliki tingkat kecerdasan yang rendah maka siswa tersebut akan sulit untuk mendapatkan nilai prestasi belajar yang baik, atau bisa dikatakan yang memiliki tingkat kecerdasan yang rendah akan mendapat prestasi yang rendah. Namun pada kenyataannya banyak siswa yang memiliki tingkat kecerdasan yang tinggi belum tentu mendapatkan nilai prestasi yang baik pula. Mungkin diakibatkan kebanyakan peserta didik yang memiliki tingkat IQ yang tinggi malas untuk belajar sehingga prestasinya pun tidak sesuai dengan tingkat kecerdasannya. Begitu juga bagi yang memiliki tingkat kecerdasan rendah pada akhirnya belum tentu mendapat prestasi yang rendah, terkadang siswa yang sebenarnya memiliki tingkat kecerdasan yang biasa saja mendapat prestasi yang baik. Sehingga ada alasan bahwa salah satu indikator penting yang mempengaruhi prestasi siswa dalam belajar selain inteligensi yaitu kebiasaan siswa dalam belajar, artinya suatu cara yang menetap pada diri siswa pada waktu tertentu misalnya saat siswa mendapatkan pelajaran, membaca literasi, menyelesaikan tugas, dan cara mengatur waktu. Di sisi lain apabila kebiasaan itu dapat dilatih akan memberikan motivasi yang kuat (Djaali dalam Rahmi: 2013). Artinya dapat dipastikan dengan adanya kemauan belajar yang baik, melalui penerapan kebiasaan belajar, maka akan diperoleh nilai belajar yang sebanding dengan faktor yang mempengaruhinya atau prestasi belajar yang jauh lebih maksimal. Sehingga kebiasaan siswa dalam belajar yang baik sangat membantu siswa dalam upaya meningkatkan prestasinya. Definisi prestasi sendiri merupakan hasil karya yang dicapai oleh siswa pada setiap menyelesaikan kompetensi belajarnya. Syaiful dalam Rahmi (2013) mengemukakan bahwa prestasi belajar adalah hasil yang diperoleh berupa kesan-kesan yang meng- 
akibatkan perubahan dalam diri individu sebagai hasil dari aktivitas dalam belajar. Seperti yang terjadi di tempat penelitian yaitu di siswa kelas XI Pemasaran 1 SMK Kartini Jember dalam mengikuti proses belajar dalam mata pelajaran Kewirausahaan. Siswa kelas XI Pemasaran 1 memiliki tingkat kecerdasan intelektual dan kebiasaan belajar yang berbeda antara siswa yang satu dengan yang lain dalam mata pelajaran Kewirausahaan, hasil prestasinya belum tentu sesuai dengan tingkat kecerdasannya serta tidak sedikit dari mereka sulit untuk memahami materi terutama dalam hal pemahaman tentang perhitungan bahan baku, biaya over head pabrik serta perhitungan harga jual. Selain itu berdasarkan pengamatan, mayoritas dari mereka kebiasaan belajarnya juga berbedabeda ada yang baik dan ada pula kebiasaan belajarnya kurang baik itu terlihat dari kurang disiplinnya mereka dalam mengerjakan tugas. Mata Pelajaran Kewirausahaan merupakan mata pelajaran yang mencakup berbagai materi salah satunya tentang perhitungan bahan baku. Oleh karena itu perlu pemahaman dan ketelitian terutama dalam hal perhitungan.

Seperti yang telah dijelaskan sebelumnya bahwa kecerdasan intelektual (Inteligensi) sangat berpengaruh terhadap tingkat prestasi siswa namun begitu, tidak hanya tingkat kecerdasan saja yang dapat mempengaruhi tingkat prestasi namun harus diimbangi dengan faktor lain yaitu kebiasaan belajar yang optimal. Jika siswa memiliki tingkat Intellectual Intelligence (IQ) yang baik serta kebiasaan belajar yang baik dan tepat akan mempermudah siswa mendapatkan prestasi yang maksimal. Oleh karena itu, peneliti ingin melakukan penelitian untuk mencari tahu apakah ada dampak Intellectual Intelligence (IQ) dengan kebiasaan pada prestasi belajar siswa.

\section{METODE PENELITIAN}

Jenis penelitian Kuantitatif yang digunakan dalam menyelesaikan penelitian ini, dengan bantuan beberapa metode pengumpulan data di antaranya observasi, kuesioner dan dokumentasi yang dibagikan kepada siswa kelas XI Pemasaran 1 SMK Kartini Jember dengan jumlah sampel 35 siswa. Sedangkan penggunaan teknik analisis data untuk menjawab hipotesis dan permasalahannya melalui uji analisis regresi linear berganda.

\section{HASIL DAN PEMBAHASAN}

Secara konseptual prestasi siswa dalam belajar dipengaruhi oleh dua unsur dari dalam diri dan luar siswa. Pada penelitian ini ingin mengetahui dampak Intellectual Intelligence (IQ) dengan kebiasaan pada prestasi belajar siswa. Untuk mengetahui sejauh mana dampak variabel $\mathrm{X}_{1}$ dan $\mathrm{X}_{2}$ terhadap $\mathrm{Y}$, maka diperlukan analisis regresi linear berganda sebagai pembuktian jikalau uji hipotesis penelitian secara parsial (uji t) dan simultan (uji F) melalui Program SPSS versi 21.0 didapatkan output dan disimpulkan sebagai berikut:

\section{Tabel 1. Hasil Analisis}

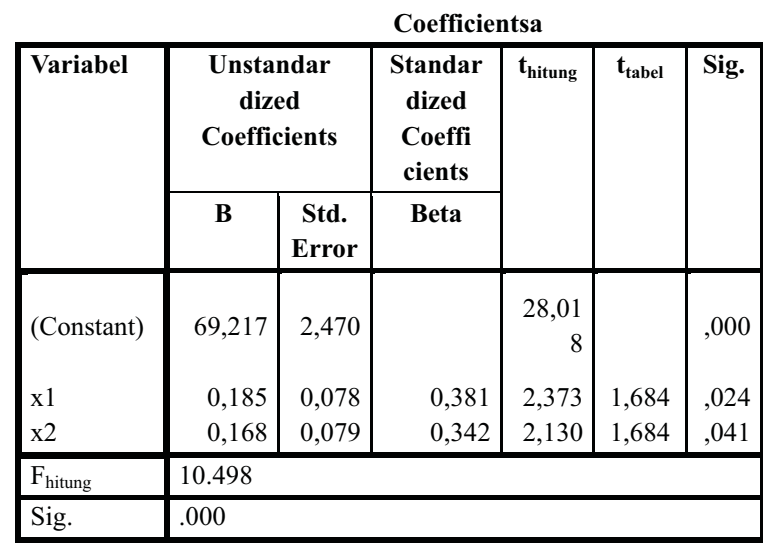

Sumber: data diolah 


\section{Dampak Intellectual Intelligence (IQ) Pada Prestasi Belajar Siswa}

Merujuk dari hasil analisis data melalui Uji $\mathrm{t}$ yaitu antara variabel Intellectual Intelligence $\left(\mathrm{X}_{1}\right)$ terhadap prestasi belajar $(\mathrm{Y})$, didapatkan bahwa nilai $\mathrm{t}_{\text {hitung }}(2.373)>\mathrm{t}_{\text {tabel }}$ (1.684) dan nilai sig $<0.05$. Maka dapat disimpulkan $\mathrm{H}_{0}$ ditolak. Hal ini menunjukkan bahwa ada dampak variabel Intellectual Intelligence $\left(\mathrm{X}_{1}\right)$ terhadap prestasi belajar (Y). Hasil tersebut juga didukung dari analisis deskriptif pada variabel Intellectual Intelligence (X1) yang dapat disimpulkan bahwa mayoritas siswa kelas XI Pemasaran 1 di SMK Kartini Jember semester gasal tahun pelajaran 2019/2020 pada indikator kemampuan memecahkan masalah, siswa tergolong dapat menyelesaikan masalah dalam hal menyelesaikan tugas dengan tepat dan cepat, dan memiliki kemampuan logika tinggi dalam berpikir untuk menemukan fakta yang akurat serta memprediksi resiko yang ada, sehingga siswa selalu berpikir kritis dan analitis, untuk dapat mengambil keputusan dengan cepat dan tepat. Pada indikator Intelegensi Verbal, siswa tergolong memiliki intelegensi verbal yang baik dalam kaitannya dengan kemampuan untuk mengenali, menyambung dan merangkai kata-kata, serta siswa memiliki kemampuan membaca, menulis, berbicara dengan baik, menunjukkan keingintahuan, dan ingin tahu secara intelektual. Sedangkan pada indikator Intelegensi Praktis, siswa tergolong memiliki intelegensi praktis dengan baik dalam hal melaksanakan tugas praktek dengan baik, mengetahui dan mengenal lingkungan sekitar. Merujuk dari hasil kesimpulan tiap indikator dari variabel Kecerdasan Intelektual (IQ), didapatkan bahwa tingkat Kecerdasan Intelektual siswa termasuk dalam klasifikasi tinggi. Hasil penelitian tersebut juga didukung oleh Walter B. Kolesnik mengatakan bahwa "in most cases there is a fairly high correlation between one's IQ, in the higher grades he receives. Selain didukung oleh teori Walter B. Kolesnik juga didukung hasil penelitian dari Uswatul dan Aditya (2013), yang mendapatkan hasil penelitiannya bahwa kecerdasan intelektual berpengaruh pada prestasi belajar.

\section{Dampak Kebiasaan Pada Prestasi Belajar Siswa}

Berdasarkan hasil analisis data melalui Uji t yaitu antara variabel kebiasaan $\left(\mathrm{X}_{2}\right)$ pada prestasi belajar (Y), didapatkan bahwa nilai $\mathrm{t}_{\text {hitung }}(2.130)>\mathrm{t}_{\text {tabel }}(1.684)$ dan nilai sig $<0.05$. Maka dapat dipastikan $\mathrm{H}_{0}$ ditolak. Artinya, ada dampak dari kebiasaan siswa $\left(\mathrm{X}_{2}\right)$ pada prestasi belajar (Y). Tentunya sesuai analisis deskriptif pada variabel kebiasaan disimpulkan bahwa mayoritas siswa kelas XI Pemasaran 1 di SMK Kartini Jember semester gasal tahun pelajaran 2019/2020 pada indikator disiplin diri tergolong memiliki disiplin diri yang baik dalam hal belajar setiap hari secara teratur, belajar bukan hanya pada saat ulangan, selalu mengikuti pelajaran di sekolah. Pada indikator waktu belajar dapat disimpulkan bahwa mayoritas siswa kelas XI Pemasaran 1 di SMK Kartini Jember semester gasal tahun pelajaran 2019/2020 tergolong memiliki waktu belajar dengan baik dalam hal mempunyai waktu belajar di rumah, memiliki waktu belajar setiap hari dalam seminggu, mempunyai daftar waktu untuk belajar. Pada indikator motivasi belajar dapat disimpulkan bahwa mayoritas siswa kelas XI Pemasaran 1 di SMK Kartini Jember semester gasal tahun pelajaran 2019/2020 tergolong memiliki motivasi belajar yang baik dalam hal belajar karena dorongan pribadi, belajar karena ingin berprestasi, tidak pernah menyerah mengerjakan tugas yang sulit, mampu memberikan dorongan pada dirinya untuk selalu maju serta merujuk pada hasil kesimpulan pada tiap indikator menunjukkan bahwa kebiasaan belajar siswa termasuk dalam klasifikasi baik. Hasil penelitian 
tersebut juga didukung oleh kajian teori yang dikemukakan oleh Djaali (2011) bahwa "kebiasaan mengandung motivasi yang kuat". Dapat dipastikan melalui motivasi belajar yang baik, melalui implementasi kebiasaan belajar yang baik juga, maka akan diperoleh prestasi belajar yang sebanding dengan faktor yang mempengaruhinya atau prestasi belajar yang jauh lebih maksimal. Selain didukung teori yang dikemukakan oleh Djaali hasil penelitian ini juga didukung Infirul (2010) dan Aditya (2013) yang memastikan terdapat pengaruh kebiasaan belajar terhadap prestasi siswa.

\section{Dampak Intellectual Intelligence (IQ) dengan Kebiasaan Pada Prestasi Belajar Siswa}

Dampak Intellectual Intelligence (IQ) dengan kebiasaan pada prestasi belajar siswa kelas XI Pemasaran 1 di SMK Kartini Jember semester gasal tahun pelajaran 2019/2020 sebesar 39,6\% ini menunjukkan adanya hubungan yang erat, meskipun masih ada pengaruh variabel lain yang tidak diteliti dalam penelitian ini. Berdasar pada tabel analisis, didapatkan hasil analisis secara simultan yaitu antara pengaruh Intellectual Intelligence $\left(\mathrm{X}_{1}\right)$ dengan kebiasaan $\left(\mathrm{X}_{2}\right)$ pada prestasi belajar dengan hasil $\mathrm{F}_{\text {hitung }}(10.498)>$ $\mathrm{F}_{\text {tabel }}(3.30)$ dan nilai sig $<0.05$. Maka dapat dikatakan $\mathrm{H}_{0}$ ditolak. Hal ini menunjukkan bahwa ada dampak yang signifikan antara Intellectual Intelligence (IQ) dengan kebiasaan pada prestasi belajar, hasil tersebut didukung teori Dimyati dan Mudjiono (2009) bahwa dalam kecerdasan intelektual dan kebiasaan siswa dalam belajar merupakan bagian dari indikator yang mempengaruhi prestasi belajar dan didukung hasil penelitian Aditya Satya Nugraha yang menunjukkan adanya hubungan kecerdasan intelektual dan kebiasaan terhadap prestasi siswa dalam belajar.

\section{PENUTUP}

\section{Simpulan}

1. Adanya dampak yang signifikan secara parsial antara Intellectual Intelligence (IQ) dengan kebiasaan pada prestasi belajar siswa di kelas XI Pemasaran 1 SMK Kartini Jember semester gasal tahun pelajaran 2019/2020.

2. Bahwa secara simultant ada dampak yang signifikan antara Intellectual Intelligence (IQ) dengan kebiasaan pada prestasi belajar di kelas XI Pemasaran 1 SMK Kartini Jember semester gasal tahun pelajaran 2019/2020.

\section{Saran}

Berkaitan dengan peningkatan kecerdasan intelektual dan kebiasaan belajar seorang pendidik harus lebih sering memberikan tes baik tulis maupun lisan pada siswa, menggunakan berbagai media pembelajaran dan memberikan tanya jawab pada saat proses belajar di kelas guna memberi stimulus pada siswa agar bisa berpikir dan membiasakan diri untuk belajar guna meningkatkan kecerdasan dan memperbaiki kebiasaan belajar siswa. Sehingga apabila kecerdasan intelektual dan kebiasaan belajar siswa lebih baik dari sebelumnya, maka akan berdampak juga pada prestasi belajar siswa tersebut. Sedangkan untuk kepentingan pengembangan penelitian selanjutnya, diharapkan temuan-temuan yang sudah didapat oleh penelitian ini bisa digunakan sebagai rujukan.

\section{DAFTAR PUSTAKA}

Andartari. (2011). Pengaruh Kemampuan Intelektual (IQ) Dan Motivasi Belajar Terhadap Hasil Belajar Siswa Pada Mata Pelajaran Akuntansi Pada SMA LABSCHOOL Rawamangun, Jurnal, Fakultas Ekonomi, UNJ Rawamangun.

Cholil dan Sugeng Kurniawan. (2011). Psikologi Pendidikan Telaah Teoritik 
dan Praktik, Surabaya: IAIN Sunan Ampel Press.

Chusna, Uswatul. (2013). Pengaruh Kecerdasan Emosional Dan Kecerdasan Intelektual Terhadap Prestasi Matematia Siswa Kelas VII MTsN Bandung Tulungagung Tahun Pelajaran 2012/2013, Skripsi, Program Studi Tadris Matematika, Jurusan Tarbiyah, Sekolah Tinggi Agama Islam Negeri (STAIN) Tulungagung.

Djaali. (2011). Psikologi Pendidikan, Jakarta: Bumi Aksara.

Djamarah, Syaiful Bahri (2002). Psikologi Belajar. Jakarta: PT. Rineka Cipta,

Dimyati dan Mudjiono. (2006). Belajar dan Pembelajaran, Jakarta: Rineka Cipta.

Satya Nugraha, Aditya. (2013). Pengaruh Antara Motivasi, Kecerdasan, Dan
Kebiasaan Belajar Matematika Siswa terhadap Prestasi Belajar Matematika Siswa Semester 2 Kelas VIII B SMP Negeri 2 Ngadirojo, Naskah Publikasi, Fakultas Keguruan Dan Ilmu Pendidikan, Universitas Muhammadiyah Surakarta.

Tati'ah, Infirul. (2010). Pengaruh Kebiasaan Belajar terhadap Prestasi Belajar Matematika Siswa Kelas VIII SMPN 2 Rejotangan Tulungagung Tahun Ajaran 2009/2010, Skripsi, Program Studi Tadris Matematika, Jurusan Tarbiyah, Sekolah Tinggi Agama Islam Negeri (STAIN) Tulungagung.

Undang-Undang Republik Indonesia No. 20 Tahun 2003 Tentang Sistem Pendidikan Nasional (SISDIKNAS). 2003. Bandung: Citra Umbara. 